\title{
TOPOLOGICAL GAMES ON PRODUCT SPACES AND ITS FUZZIFICATION
}

Bidyanand Prasad

Department of Mathematics, TU

TRM Campus, Birganj

\author{
B.P. Kumar
}

University Dept. of Mathematics

B.R.A.B.University, Muzaffarpur, Bihar

\begin{abstract}
This paper is concerned with the introduction of an infinite positional game of pursuit and evasion over an ideal of a topological space. A topological game has been played over some new D-product and C-product spaces of two Hausdorff topological spaces. Perfect information, decisions and goals in a game may not be feasible. Hence, fuzzy set theory has been applied in this paper to obtain better results.
\end{abstract}

\section{Keywords}

Topological games, product spaces, fuzzification, coalition, feasible solution.

\section{Introduction}

Over an ideal of a topological space, Kumar (1982) has played a topological game. By introducing the concept of rectangle in a topological product spaces, some special types of product are studied. A game is played over such products. It is explained how fuzzy set theory can be applied to obtain better results lastly.

Games over an ideal of a topological space Let $G(I, X)$ be an infinite positional game of pursuit and evason over I where $\mathrm{X}$ is a topological space and I ᄃ $\subset \mathrm{P}(\mathrm{X})$ s.t. I is closed with respect to union and I possesses hereditary property. Such collection I is called an ideal over $\mathrm{X}$.

This game is played as follows: There are two players-P (Pursuer) and E (Evader), They choose alternately consecutive terms of a sequence $<$ En $/ \mathrm{n} \in \mathrm{N}$, where $\mathrm{N}=\{0,1,2, \ldots \ldots \ldots \ldots$. $n, \ldots . ..\}>$ of subsets of $X$ s.t. each player knows $\mathrm{I}, \mathrm{E}_{\mathrm{o}}, \mathrm{E}_{1}, \ldots \ldots . . . . \mathrm{En}$ when he is choosing En+1. Sequence $<E n>$ of subset of $X$ is said to be a play of the game if for all $n \in N$ the following holds:

i. $\quad \mathrm{E}_{\mathrm{o}}=\mathrm{X}$

ii. $\mathrm{E}_{1}, \mathrm{E}_{3}, \mathrm{E}_{5}, \ldots \ldots \ldots . . . \mathrm{E}_{2+1}$ are the choice of P.

iii. $\quad \mathrm{E}_{1}, \mathrm{E}_{3}, \mathrm{E}_{5} \ldots \ldots \ldots \ldots \ldots \ldots . . . . . \mathrm{E}_{2 \mathrm{n}+1} \in \mathrm{I}$. 
iv. $\mathrm{E}_{2}, \mathrm{E}_{4}, \mathrm{E}_{6} \ldots \ldots \ldots \ldots \ldots . . . . . \mathrm{E}_{2 \mathrm{n}+2}$ are the choice of $\mathrm{E}$.

$\begin{array}{ll}\text { v. } & \mathrm{E}_{1}, \mathrm{E}_{2}, \subset \subset \mathrm{E}_{n} ; \mathrm{E}_{3}, \mathrm{E}_{4} \subset \subset \mathrm{E}_{2} \ldots \ldots \ldots . . ; \\ \mathrm{E}_{2 \mathrm{n}+1}, \mathrm{E}_{2 \mathrm{n}+2} \subset \subset \mathrm{E}_{2 \mathrm{n}} .\end{array}$

$\begin{array}{ll}\text { vi. } & \mathrm{E}_{1} \cap \cap \mathrm{E}_{2}=\phi, \mathrm{E}_{3} \cap \cap \mathrm{E}_{4}=\phi, \ldots \ldots \ldots . . . \\ \mathrm{E}_{2 \mathrm{n}+1} \cap \cap \mathrm{E}_{2 \mathrm{n}+2}=\phi .\end{array}$

If $\cap \cap<\mathrm{E}_{2 n}>=\phi$ then player $\mathrm{P}$ wins the play, otherwise Evader wins the play.

A finite sequence $<\mathrm{E}_{\mathrm{m}} / \mathrm{m} \leq \mathrm{n}>$ is admissible for the game if the sequence $<\mathrm{E}_{\mathrm{o}}, \mathrm{E}_{1}, \ldots \ldots . \mathrm{E}_{\mathrm{n}}$, $\phi, \phi, \phi, \ldots . . . \phi>$ is a play of the game. For admissible sequence $<\mathrm{E}_{\mathrm{o}}, \ldots \ldots . ., \mathrm{E}_{\mathrm{n}}>$ and even $\mathrm{n}$ if $\mathrm{s}:<\mathrm{E}_{\mathrm{o}}, \ldots \ldots . \mathrm{E}_{\mathrm{n}}>$ ? $\mathrm{P}(\mathrm{X})$ and $\mathrm{s}\left(<\mathrm{E}_{\mathrm{o}}, \ldots \ldots . \mathrm{E}_{\mathrm{n}}>\right)=$ $E_{n+1}$ then $s$ is a strategy for player P.S is said to be strategy for evader $\mathrm{E}$ if $\mathrm{n}$ is odd.

A strategy $\mathrm{s}$ is said to be winning for player $P$ in the game $G(I, X)$ if $P$ wins each play of the game with the help of this s. Similarly $\mathrm{s}$ is said to be winning for $\mathrm{E}$ if $\mathrm{E}$ wins each play of the game with the help of s. We denote by $\mathrm{P}(\mathrm{I}, \mathrm{X})$, the set of all winning strategies of $P$ in the game $G(I, X)$ and by $E(I, X)$, the set of all winning strategies of $\mathrm{E}$ in the game $\mathrm{G}(\mathrm{I}, \mathrm{X})$. A topological space $\mathrm{X}$ is said to be I-like if the set of all winning strategies of player $\mathrm{P}$ is not empty i.e. if $\mathrm{P}(\mathrm{I}, \mathrm{X}) \neq \phi$.

Similarly, a space $\mathrm{X}$ is said to be anti I-like if the set of all winning strategies of player $E$ is not empty. That is $\mathrm{E}(\mathrm{I}, \mathrm{X}) \neq \phi$

The game $G(I, X)$ is said to be determined, if $\mathrm{P}(\mathrm{I}, \mathrm{X}) \neq \varphi$ or $\mathrm{E}(\mathrm{I}, \mathrm{X}) \neq \varphi$

\section{Products of topological spaces}

A subset A x B of a topological product space $\mathrm{X} \times \mathrm{Y}$ is called a rectangle. A rectangle $\mathrm{E}$ is said to be:

i. Cozero if E' \& E” are cozero in X x Y ;

ii. Zero if E' \& E” are zero in X $\mathrm{x} Y$;

iii. Open if E' \& E” are open in X x Y ;

iv. Closed if E' \& E” are closed in X x Y

where E' \& E” are the projections of E into X and $Y$ respectively so that $E=E^{\prime} x E^{\prime \prime}$.

A topological product $\mathrm{X} \times \mathrm{Y}$ is said to be strong rectangular if each locally finite open cover of X $x$ Y has a locally finite refinement by cozero rectangles.

The following conditions are seen to be equivalent:

i. The product $\mathrm{X} \times \mathrm{Y}$ is strongly rectangular.

ii. Each finite open cover of X x Y has a locally finite refinement by cozero rectangles.

iii. For each closed subset $F$ and each open set $\mathrm{U}$ of $\mathrm{X} \times \mathrm{Y}$ with $\mathrm{F} \subset \subset \mathrm{U}$, there is a locally finite collection $\mathrm{W}$ bv cozero rectangles s.t. $F \subset \subset \cup W$ $\subset \subset \mathrm{U}$

iv. $\quad \mathrm{X} x \mathrm{Y}$ is normal and for each zero-set $F$ and each cozero-set $U$ of $X x$ Y with $\mathrm{F} \subset \subset \mathrm{U}$, there is a locally finite collection $\mathrm{W}$ bv cozero rectangles such that F W U.

v. There exists a continuous map

$\mathrm{f}: \mathrm{X} x \mathrm{Y}$ ? $[\mathrm{o}, 1]$ such that $\mathrm{f}(\mathrm{x}, \mathrm{y})=\sum \mathrm{g}_{\mathrm{t}}(\mathrm{x}) \mathrm{h}_{\mathrm{t}}$ $(y), t \in$ Twhere $g_{t}: x$ ? $[0,1]$ and $h_{t}: Y$ ? $[0,1]$ are continuous.

\section{Games over spaces}

Each topological space considered in this paper is assumed to be a Hausdorff space. $\mathrm{N}$ denotes the set of all natural numbers and $\mathrm{m}$ denotes an infinite cardinal number. Also let $\mathrm{L}=\left\{\mathrm{E}_{1} \mid \mathrm{E}_{1}\right.$ are closed subsets of $\left.\mathrm{X}\right\}$.

There are two players $\mathrm{P}$ and E. Player $\mathrm{P}$ chooses a closed set $E_{1}$ of $X$ with $E_{1} \in L$ and player $E$ chooses an open set $U_{1}$ of $X$ with $E_{1}$ $\mathrm{U}_{1}$.

Again, player $\mathrm{P}$ chooses a closed set $\mathrm{E}_{2}$ of $\mathrm{X}$ with $E_{2} \in L$ and plaver $E$ chooses an open set $\mathrm{U}_{2}$ of X with $\mathrm{E}_{2} \quad \mathrm{U}_{2}$ and so on.

The infinite sequence $<\mathrm{E}_{1}^{2}, \mathrm{U}_{1}, \mathrm{E}_{2}, \mathrm{U}_{2}, \ldots . . .>$ is a play of $G(L, X)$. Player $P$ wins the play $<E_{1}, E_{1}$, $E_{2}, U_{2} \ldots \ldots . . .>$ if $\{U n: n \in N\}$ covers $X$, otherwise player E wins.

A finite sequence $<E_{1}, U_{1}, \ldots \ldots . .$. . En $U n>$ of subsets in $X$ is said to be admissible for $G(L$, 
$\mathrm{X})$ if the infinite sequence $<\mathrm{E}_{1}, \mathrm{U}_{1} \ldots \ldots . . . \mathrm{En}, \mathrm{Un}$, $\$, 4$.......... is a play of $\mathrm{G}(\mathrm{L}, \mathrm{X})$.

A function $s$ is said to be a strategy for player $P$ in $G(L, X)$ if the domain of $s$ consists of the void sequence $\&$ and the finite sequence $<\mathrm{U}_{1}, \ldots \ldots . . . . . \mathrm{Un}>$ of open sets in $\mathrm{X}$ and if $\mathrm{s}(\mathrm{q})$ and $\mathrm{s}\left(\mathrm{U}_{1}, \ldots . . . . . . ., \mathrm{Un}\right)$ are closed in $\mathrm{X}$ and belong to $\mathrm{L}$.

A strategy s for player $\mathrm{P}$ in the game $\mathrm{G}(\mathrm{L}, \mathrm{X})$ is said to be winning if he wins each play $<\mathrm{E}$, $\mathrm{U}_{1}, \mathrm{E}_{2}, \mathrm{U}_{2}, \ldots \ldots \ldots . . . \mathrm{in} \mathrm{G}(\mathrm{L}, \mathrm{X})$ such that $\mathrm{E}_{1}=\mathrm{s}$ and $E n+1=s\left(U_{1}, \ldots \ldots . ., U n\right)$, for all $n \in N$.

The Following notations are used:

DL - The class of all spaces which have a discrete closed cover consisting of members of $\mathrm{L}$.

FL - The class of all spaces which have a finite closed cover consisting of members of $\mathrm{L}$.

C - The class of all compact spaces.

$\mathrm{Cm}$ - The class of $\mathrm{m}$-compact space.

$I_{1}, I_{2}-$ Arbitary classes of spaces possessing hereditary property s.t.

$I_{1} \times I_{2}=\left\{X x Y: X \in I_{1}\right.$ and $\left.Y \in I_{2}\right\}$.

We define the following two products spaces: Def 1 : D-Product: A Product space X $\mathrm{x}$ Y is said to be a D-product if for each closed set $\mathrm{M}$ of X x Y and each open set $\mathrm{O}$ of X x Y with M

$\mathrm{O}$, there is a o-discrete collection I by closed rectangles in $\mathrm{X} \times \mathrm{Y}$ such that $\mathrm{M}$<smiles>[AlH2]</smiles>

For a closed rectangle $\mathrm{R}$ in $\mathrm{X} \times \mathrm{Y}, \mathrm{R}^{\mid}$and $\mathrm{R}^{\|}$denote the projection of $\mathrm{R}$ into $\mathrm{X}$ and $\mathrm{Y}$ respectively. Thus $\mathrm{R}$ is a closed rectangle in $\mathrm{X}$ $\mathrm{x} Y$ iff $\mathrm{R}^{\prime}$ and $\mathrm{R}$ " are closed in $\mathrm{X} \& \mathrm{Y}$ and $\mathrm{R}$ is an open rectangle in $\mathrm{X} \times \mathrm{Y}$ iff $\mathrm{R}^{\mathrm{I}}$ and $\mathrm{R}^{\|}$are open in $X$ and $Y$ such that $R=R^{\prime}$ and $R^{\|}$.

Def 2: C-Product space $\mathrm{X} \times \mathrm{Y}$ is said to be a C-product if for each closed set $\mathrm{M}$ of $\mathrm{X} \times \mathrm{Y}$ and each open set $\mathrm{O}$ of $\mathrm{X} \times \mathrm{Y}$ with $\mathrm{M}$

$\mathrm{O}$ there is a countable collection $\mathrm{J}$ by closed rectangles in $\mathrm{X} \times \mathrm{Y}$ such that $\mathrm{M}$

O.

The following result follows easily.Theorem:

(1) Let $X$ and $Y$ be spaces such that $X x Y$ is a

$D$-Product. If player $P$ has winning strategies in $G(I, X)$ and $G(I, Y)$, then he has a winning strategy in $\mathrm{G}\left(\mathrm{D}\left(\mathrm{I}_{1} \times \mathrm{I}_{2}\right), \mathrm{X} \times \mathrm{Y}\right)$.
Now, we prove the following.

Theorem: (2) Let X be a collection wise normal space and $Y$ a subparcompact space with $X$ $(\mathrm{Y}) \leq \mathrm{m}$. If player $\mathrm{P}$ has a winning strategy in $\mathrm{G}(\mathrm{DCm}, \mathrm{X})$, then every open cover of X $\mathrm{x} Y$ with power $\leq \mathrm{m}$ has a o-discrete refinement by closed rectangles in $\mathrm{X} x \mathrm{Y}$.

Proof: Let $\mathrm{s}$ be a winning strategy of player $P$ in $\mathrm{G}(\mathrm{DCm}, \mathrm{X})$. Let $\mathrm{C}$ be an arbitrary open cover of X $\mathrm{x}$ Y with $\mid \mathrm{c}_{i} \leq \mathrm{m}$.

We construct:

i. a sequence $\{\mathrm{J}: \mathrm{n} \geq 0\}$ collections of closed rectangles in $\mathrm{X} \times \mathrm{Y}$;

ii. sequence $\{<\Re n, \leq \Psi n>: n \geq 0\}$ of the pairs of collections Rn by closed rectangles in $\mathrm{X} \mathrm{x} \mathrm{Y;}$

iii. the function $\Psi \mathrm{n}$ : $\Re$ n? the following five conditions:

a) Jn is o-discrete in $\mathrm{X} x \mathrm{Y}$.

b) $\Re \mathrm{n}$ is o-discrete in $\mathrm{X} \times \mathrm{Y}$.

c) Each $F \in J n$ is contained in some $\mathrm{G} \in \mathrm{C}$.

d) If (x, y) $\in$ Rn-1 $\in \Re$ R-1 and (x, y) $₫$ Jn.

Then there is $\mathrm{Rn} \in \mathfrak{R}$ n such that $(\mathrm{x}, \mathrm{y}) \in$ $\mathrm{Rn}$ and $\Psi \mathrm{n}(\mathrm{Rn})=\mathrm{Rn}-1$.

e) for an $\mathrm{R} \in \Re \mathrm{R}$, let $\mathrm{Un}=\mathrm{X}-\mathrm{R}$ and $\mathrm{Uk}=\mathrm{X}-\left(\Psi \mathrm{k}+1 \text { o....... } \Psi_{\mathrm{n}}(\mathrm{R})\right)^{\prime}$, for $1 \leq \mathrm{k} \leq \mathrm{n}-1$.

We put $\mathrm{E}_{1}=\mathrm{s}(\phi)$ and $\mathrm{E}_{\mathrm{k}+1}=\mathrm{s}\left(\mathrm{U}_{1}, \ldots \ldots \ldots . . . \mathrm{Uk}\right)$ for $1 \leq \mathrm{k} \leq \mathrm{n}-1$.

Then the finite sequence $<E_{1}, U_{1} \ldots$ En, Un, $>$ is admissible for $\mathrm{G}(\mathrm{DCm}, \mathrm{X})$.

Let $J_{\mathrm{o}}=\{\phi\}$ and $\Re_{\mathrm{o}}=\{\mathrm{X} \times \mathrm{Y}\}$.We suppose that the above $\{\mathrm{Ji},: \mathrm{i} \leq \mathrm{n}\}$ and $\{\langle\Re \mathrm{R}, \Psi \mathrm{i}\rangle: \mathrm{i} \leq \mathrm{n}\}$ are already constructed.

We pick and $R \in \Re n$.

Let $<E_{1}, U_{1}, \ldots . . .$. . En, Un $>$ be the admissible sequence in $\mathrm{G}(\mathrm{DCm}, \mathrm{X})$.

Hence there is a discrete collection $\{C \alpha: \alpha \in$ 
$\Omega \mathrm{R}\}$ by m-compact closed sets in $\mathrm{R}$ such that $\mathrm{s}\left(\mathrm{U}_{1}\right.$, , Un) ? $\mathrm{R}^{\prime}=\cup\{\mathrm{C} \alpha: \alpha \in \Omega \mathrm{R}\}$.

We can a choose discrete colletion $\{\mathrm{W} \alpha: \alpha \in$ $\Omega(\mathrm{R})\}$ of open sets in R' s.t. C $\alpha \subset \mathrm{W} \alpha$, for all $\alpha$ $\in \Omega(\mathrm{R})$.

Since $C \alpha$ is m-compact, $i c \mid \leq m, \chi(Y) \leq m$ and $\mathrm{R}$ ” is subparacompact.

There is a collection $\mathrm{J}^{\alpha}{ }_{\mathrm{n}+1}=\left\{\mathrm{CI} \mathrm{U}^{\alpha, \mathrm{i}}{ }_{\lambda} \mathrm{x} \mathrm{H}_{\lambda}\right.$ : i $=\mathrm{I}, \ldots . . . \mathrm{k}$, and $\lambda \in \wedge(\mathrm{k})\}$ by closed rectangle in $R$. which satisfying the following four conditions:

(1) Each $U_{\lambda, i}^{\alpha, i}$ is open in R'.

(2) $\mathrm{C}_{\alpha} \subset \cup\left\{\mathrm{U}_{\lambda, \mathrm{i}}^{\alpha}: \mathrm{i}=1, \ldots \ldots \ldots \ldots \mathrm{k}_{\curlywedge}\right\} \subset \mathrm{W}_{\alpha}$

(3) Each $\mathrm{C}_{1} \mathrm{U}^{\alpha, i}{ }_{\lambda} \times \mathrm{H}_{\lambda}$ is contained in some $\mathrm{G} \in \mathrm{C}$.

(4) $\left\{\mathrm{H}_{\lambda}: \in \wedge(\alpha)\right\}$ is a $\sigma$-discrete closed cover of R”. Then $J_{n+1}(R)=U\left\{J^{\alpha}{ }_{n+1}\right.$ : $\alpha \in \Omega(R)\}$ is a $\sigma$-discrete in $X x Y$.

Put $\mathrm{U}_{\lambda}^{\alpha,}=\left\{\mathrm{CI} W_{\alpha}-\mathrm{U}\left\{\mathrm{U}^{\alpha, \mathrm{i}}{ }_{\lambda}: \mathrm{i} \leq \mathrm{i} \leq \mathrm{k}_{\curlywedge}\right\} \times \mathrm{H}_{\curlywedge}\right\}$, for all,$\in^{\wedge}(\mathrm{k})$

Again put $\mathrm{R}=\left(\mathrm{R}^{\prime}-\cup\left\{\mathrm{W} \alpha: \alpha \in \Omega^{\circledR}\right\} \mathrm{x} \mathrm{R}\right.$ ”.

Moreover, we put $\Re \mathrm{n}_{+1}(\mathrm{R})=\left\{\mathrm{R} \cup\left\{\mathrm{R}_{\lambda}^{\alpha}: \lambda \in(\alpha)\right\}\right.$ and $\lambda \in \Omega(\mathrm{R})\}$.

Then $\mathfrak{R n} \mathrm{n}_{+1}(\mathrm{R})$ is also $\sigma$-discrete collection by closed rectangles in $R$.

We set $J n_{+1}=U\left\{J n_{+1}(R): R \in \Re n\right\}$ and $\Re n_{+1}=U$ $\left\{\Re \mathrm{n}_{+1}(\mathrm{R}): \mathrm{R} \in \mathfrak{R} \mathrm{n}\right\}$.

The function $\Psi_{\mathrm{n}+1}: \Re \mathrm{n}_{+1}$ ? $\mathrm{Rn}$ defined as $\Psi_{\mathrm{n}+1}$ $\left(\Re \mathrm{n}_{+1}(\mathrm{R})\right)=\{\mathrm{R}\}$, for all $\mathrm{R} \in \mathfrak{R}$.

From (a), Jn+1 and $\Re n+1$ are o-discrete in $\mathrm{X}$ $x$ Y..

The conditions (a) and (b) are satisfied.

By (3), then the condition (c) is also satisfied.

The conditions (d) and (e) are very clear.

Let $J=\{\mathrm{Jn}: \mathrm{n} \in \mathrm{N}\}$.

We can easily show that $\mathrm{J}$ is a cover of $\mathrm{X} x \mathrm{Y}$. Therefore $\mathrm{J}$ is a o-discrete refinement of $\mathrm{C}$ by closed rectangles in $\mathrm{X} x \mathrm{Y}$.

With the consequences of the above theorem and assuming PCm to be the class of all product spaces with the first factor being m-compact, the following can be obtained easily:I. Let $\mathrm{X}$ be a collectionwise normal space and $Y$ be a subparacompact space with $\chi(\mathrm{Y}) \leq \mathrm{m}$. If player $\mathrm{P}$ has a winning strategy in $\mathrm{G}(\mathrm{DCm}, \mathrm{X})$, then $\mathrm{X} \mathrm{x} Y$ is a D-product.
II. Let $\mathrm{X}$ be a paracompact space and $\mathrm{Y}$ be a subparacompact space.

III. Let $\mathrm{X}$ be a collectionwise noromal space and $\mathrm{Y}$ be a subparacomact space with $\mathrm{X}(\mathrm{Y})$ $\leq \mathrm{m}$. If player $\mathrm{P}$ has a winning strategy in $\mathrm{G}$ (DCm, X), then he has a winning strategy in $\mathrm{G}(\mathrm{D}(\mathrm{PCmm}), \mathrm{X} \times \mathrm{Y})$.

\section{Fuzzy set coalition}

A game is determined by information, decisions and goals. But human notions (ideas) and decisions are fuzzy. For, a man with immense entropy functions may err, set right and understanding a little may increases his understanding in the pursuit of some knowledge. Therefore, in a game, perfect information, decisions \& goals may not be feasible. We are therefore, led to the introduction of fuzzy games.

Let $G=(N, v)$ be a nonfuzzy game of the set $\mathrm{N}=\{1,2,3, \ldots, \mathrm{n}\}$ of $\mathrm{n}$ players in which $\mathrm{v}: \mathrm{s}$ ? $\mathrm{R}$ is a real valued function (characteristic function) from a family of coalition $\mathrm{S} \quad \mathrm{N}$ to the set of real numbers R. Hence $v(A)$ means the gain which a coalition. A can acquire only through the action of $\mathrm{A}$, the coalition $\mathrm{A}$ can be specified by the characteristic function $\tau A$ (i) $= \begin{cases}1 & \text { if } i \in A ; / o\end{cases}$

A rate of participation $\tau A$ ( $i$ ) of a player $i$ is defined by

$\tau \mathrm{A}(\mathrm{i})=1$, if a player i participates in $\mathrm{A}$ and

$\tau \mathrm{A}$ (i) $=0$, if a player i does not participate in A.

Consequently, a coalition $\mathrm{A}$ is represented by $\tau \mathrm{A}=(\tau \mathrm{A}(1), \tau \mathrm{A}(2), \ldots \ldots . \tau \mathrm{A}(\mathrm{n}))$.

A fuzzy coalition $\tau$ is defined as a coalition in which a player i can participate with a rate of participation $\tau 1 \in[0,1]$ instead of $\{0,1\}$. The characteristic function of a fuzzy game is a real valued function $\mathrm{f}:$ [0.1] $\mathrm{n}$ ? $\mathrm{R}$ which specifies a real number $f(\tau)$ for any fuzzy coalition $\tau$.

This fuzzy game is denoted by $F G=(\mathrm{N}, \mathrm{f})$.

By obtaining this fuzzy game, we can have the corresponding results of previous section easily which may produce better results. 


\section{Conclusion}

In a field of decision theory, game theory has a remarkable importance. To play a game over a Hausdorff topological space, a new approach has been presented in this paper. Human ideas, decisions and goals determine a game but these notions are fuzzy in nature. Hence in a game, perfect information, decisions and goals may not be feasible. A good attempt has been made to apply fuzzy set theory to obtain feasible solution for a proposed problem of real life which may be a very useful tool for the researcher working in the field of fuzzy systems.

\section{References}

Engelking, R.(1968). Outline of general topology. Amsterdam: North Holland Publishing Company.

Kumar, B.P. (1982). Lattice and topological approach to game theory, Doctoral dissertation, Bhagalpur University, Bhagalpur, Bihar.

Von, Neumann (1947). Theory of games and economic behavior $\left(2^{\text {nd }}\right.$ ed). Prinston: Prinston University Press.

Kumar, B.P. \& Kumar, Sanjay (2004). Covering property of spaces defined by games and its fuzzification. Proceedings of Advances in Mathematics and its Application. ISMAMS. 